\title{
The Effect of Timing of Shade on Development, Dry Matter Production and Light-Use Efficiency in Groundnut (Arachis hypogaea L.) under Field Conditions
}

\author{
C. M. StirlingA,B, J. H. Williams C, C. R. Black and C. K. OngC \\ ADepartment of Physiology and Environmental Science, University of Nottingham, \\ School of Agriculture, Sutton Bonington, LE12 SRD, United Kingdom. \\ BPresent address: Department of Biology, University of Essex, Wivenhoe Park, Colchester, \\ CO4 3SQ, United Kingdom. To whom correspondence should be addressed. \\ CInternational Crops Research Institute for the Semi-Arid Tropics (ICRISAT), Patancheru PO, \\ Andrha Pradesh 502324, India.
}

\begin{abstract}
During the rainy season in India, bamboo screens intercepting approximately $46 \%$ of the incident light were used to simulate the effect of shading by a cercal grown as an intercrop with groundnut (Arachis hypogaea L.). The treatments comprised an unshaded control and two durations of shading extending from peg initiation (T1) and the onset of pod filling (T2) to final harvest.

Plant height was greatest in the $\mathrm{Tl}$ crop, but the maximum rates of leaf development on the main stem, leaf area expansion and pod production were similar in all crops. Shading appeared to reduce the rate of the linear growth phase because the reduced light interception was not entirely offset by an increase in light-use efficiency. Premature senescence in the shaded crops coincided with the virtual cessation of pod production, although continued allocation of dry matter to reproductive structures in the $\mathrm{T} I \mathrm{crop}$ resulted in a greater proportion of pods being filled at final harvest than in the other treatments.

The responses of groundnut to timing of shade are discussed in terms of their implications for the sclection of improved crop combinations for intercropping.
\end{abstract}

\section{Introduction}

Traditional cropping systems such as intercropping may provide substantial yield advantages over sole crops due to their improved temporal (Natrajan and Willey 1980; Reddy et al. 1980; Willey and Osiru 1972) and spatial (Harris et al. 1987; Reddy and Willey 1981) use of resources. However, in the case of cereal-legume combinations, these advantages often arise because the improved performance of the cereal more than compensates for yield losses in the associated legume crop (Ofori and Stern 1987).

The poorer performance of legumes when intercropped may be partly because the quantity of light reaching their canopy is reduced by the taller companion crop. For example, groundnut intercepted $27 \%$ less light when grown with millet than alone (Marshall and Willey 1983), while total radiation incident on soybean was reduced by $25 \%$ when intercropped with cassava (Tsay et al. 1985). Furthermore, pod yield in soybean was $17 \%$ lower when grown with tall rather than short varieties of maize (Thompson et al. 1976), while shading by cassava reduced individual pod weight and pod number per plant relative to the sole crop (Kou et al. 1977). Similarly, under irrigated conditions, groundnut produced $13 \%$ fewer pods when intercropped with sorghum, although mean pod weight was $11 \%$ greater than in the sole crop (Harris and Natrajan 1987).

In intercropped groundnut systems, the stage of development at which shading is most severe depends upon the duration and relative growth rates of the component species. In semi-arid regions, groundnut is commonly grown in combination with cereals such as millet and sorghum where there is little difference between harvest dates (Willey et al. 1986). Consequently, the more rapid growth and canopy development of the cereal imposes shading during most of the reproductive phase in groundnut. Alternatively, 
groundnut may be grown with longer-duration, slower-growing crops such as cassava and pigeonpea, restricting shading mainly to the later stages of pod-fill.

Owing to the economic and nutritional value of legumes in semi-arid regions, they are often grown as the major component of intercrops where it is important that yields are maintained close to those expected from sole cropping systems. One method of improving the yield of intercropped legumes would be to select for species combinations which reduce the degree of shading during the stages of growth most critical in determining final pod yield. This can be achieved only with an improved understanding of the responses of tropical legumes to shading at different growth stages. To examine the influence of low light on growth and development in intercropped groundnut, bamboo screens were used to simulate the effect of shading by either long or short duration cereals.

\section{Materials and Methods}

The experiment was conducted during the rainy season at ICRISAT Center near Hyderabad, India $\left(17^{\circ} 32^{\prime}\right.$ N.. $78^{\circ} 16^{\prime}$ E.). Full details of experimental site, soil type and crop management are given by Stirling (1988).

Groundnut seeds were sown by hand on 17 June at $10 \mathrm{~cm}$ intervals in rows running cast to west and $30 \mathrm{~cm}$ apart. Heavy rain $(37 \mathrm{~mm})$ fell during the first week after sowing and mean emergence was close $1090 \%$ in all plots. At 17 days after sowing (DAS), every fourth row of groundnut in each plot was removed to give a final population of approximately 25 plants $\mathrm{m}^{-2}$. Diammonium phosphate $(18 \% \mathrm{~N}$, $46 \% \mathrm{P}_{2} \mathrm{O}_{5}$ ) was applied as a basal dressing at a rate of $100 \mathrm{~kg} \mathrm{ha}^{-1}$, and all plots were regularly handweeded and sprayed when necessary with dimethoate or endosulphan to control pests. Irrigation was applied at weekly intervals except during periods when heavy rain fell.

\section{Design and Treatments}

Treatments comprising an unshaded control and two durations of shade extending from 40 (TI) and 70 (T2) DAS to final harvest (101 DAS) were laid out in four randomized blocks. Each plot was $15 \times 15 \mathrm{~m}$ in area and contained 39 rows. Shade was provided by a bamboo weave designed to exclude approximately $46 \%$ of sunlight when placed obliquely above the crop (Fig. 1). Wooden stakes, $1.5 \mathrm{~m}$ tall, were placed at $2.5 \mathrm{~m}$ intervals along the rows from which the groundnut seedlings had been removed at 17 DAS. Horizontal poles connected to these stakes at heights of 0.3 and $1.0 \mathrm{~m}$ above the ground provided a rigid support for the bamboo screen, which was held over the crop at an angle of about $45^{\circ}$ to the normal above the northernmost row (Fig. 1). Thus, the degree of shading decreased progressively across the northern (G3), middle (G2) and southern (G1) rows, simulating the varying intensity of shade imposed by an intercrop sown in a replacement series of one row of cereal to three rows of groundnut (Marshall and Willey 1983). The screens were designed to simulate the reduced irradiances experienced by intercrop groundnut and eliminate the competitive interactions with associated cereals for water and nutrients. However, as essentially neutral filters, they would not reproduce the changes in spectral composition caused by living barricrs. The preferential depletion of photosynthetically active radiation (PAR) by the taller component of intercrops would therefore tend to amplify the effects on groundnut growth reported in this paper.

\section{Growth Analysis}

A map derived from the population count at 19 DAS was used to select individual plants randomly for regular growth analysis, avoiding areas where roots might have been damaged during insertion of the wooden stakes. Ten plants were harvested at approximately weekly intervals from each of rows $\mathrm{Gl}$, G2 and G3 in all plots to ensure that reliable treatment means were obtained. After recording developmental measurements, the plants were subdivided into stems, leaves and pods, and oven-dried to constant weight at $80^{\circ} \mathrm{C}$.

At the first two growth analyses when the plants were small, mean leaf area per plant was calculated from subsamples of four plants randomly selected from each row in the plot. When the plants became larger, grab-samples of leaves were taken and mean leaf area per plant was calculated as the product of total leaf dry weight and specific leaf area (SLA), which was derived from the area and corresponding dry weight of the grab-sample. Population counts at 19 DAS and final harvest (101 DAS) showed no marked or systematic variation between treatments, but almost $10 \%$ fewer plants survived to final harvest than had emerged at 19 DAS. 


\section{Radiation Measurements}

Daily incoming solar radiation $(300-3000 \mathrm{~nm})$ was measured using a Kipp solarimeter situated within $\mathbf{4 0 0} \mathrm{m}$ of the experimental site. An instrument termed the 'mousc', full details of which are given by Matthews $e t$ al. (1986), was used to determine fractional radiation interception $(300-3000 \mathrm{~nm})$ by the bamboo screen and crop canopy (cf. Fig. 1). Bricfly, a silicon photovoltaic cell (Ferranti Ltd) attached to an aluminium block was fitted inside a $1.4 \mathrm{~m}$ long aluminium tube. through which the sensor was moved by means of a pulley system. A data logger (Omnidata, Logan, Utah, U.S.A.) was programmed to scan the output signal from the sensor and record the highest voltage received as the sensor passed under each of 70 holes drilled at $2 \mathrm{~cm}$ intervals along the upper surface of the tube (Matthews et al. 1986).

Readings were confined to two experimental blocks to minimize the time-lag and associated variation in cloud cover between supposedly contemporary measurements. These measurements were assumed to be representative of the experimental area as a whole, since growth analysis showed no marked variation between replicates. Incident and transmitted radiation were measured at three times a day on 10 occasions between 48 and 92 DAS. During each period, two sets of measurements were recorded above and below the canopy in each plot, giving a total of four measurements for each position in specific treatments.

Intercepted radiation was calculated by approximating the crop canopy to a rectangular box (Fig. I) as described by Marshall and Willey (1983). The data logger was programmed to scan only 45 of the 70 holes, corresponding to a distance of $90 \mathrm{~cm}$ and hence a unit transect of crop containing three rows of groundnut. The differences between radiation levels at surfaces $A$ and $B$ and $C$ and $A$ (Fig. 1) were respectively assumed to represent interception by the foliage and the bamboo screen.

C
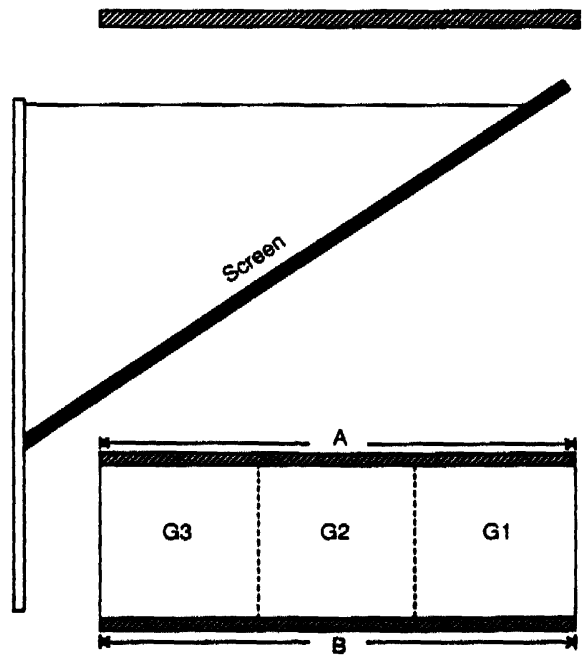

Fig. 1. Position of radiation measurements. A denotes radiation incident on a unit transect of crop and its component rows $\mathrm{G} 1, \mathrm{G} 2$ and $\mathrm{G3}$, B represents radiation transmitted to the soil surface beneath a unit transect of crop, and $C$ is total incoming radiation.

Daily mean fractional interception $(f)$ was calculated from separatc estimates madc between 0800 and 1000,1200 and 1400 and 1600 and 1800 hours (IST), where the individual values were assumed to be representative of the morning, midday and evening phases (3,6 and $3 \mathrm{~h}$ respectively) of the approximately 12-h long photoperiod during the rainy season (Stirling 1988). By calculating daily fractional interception as a weighted mean, provision was made for the possibility of diurnal variation in canopy interception (Monteith 1969; Muchow 1985). Although measurements were not extended to the early morning and late evening, when solar angle changes rapidly, any inaccuracy in the estimation of $f$ was assumod to be negligible in terms of cumulative light interception and dry matter production (Monteith 1969). 


\section{Results}

Vegetative and Reproductive Development

Shading throughout reproductive development (TI) significantly reduced branch and pod numbers, but increased specific leaf area and internode length, while shading restricted to the pod-filling stage (T2) had no marked effect on development (Table 1a). Main stem height was already significantly greater in the TI crop by 45 DAS, and was $24 \%$ greater at final harvest than in the control (Fig. 2). A much smaller increase in the main stem height was evident in the $T 2$ crop, but the response was not significant.

Table 1. The effect of shading on (a) plant morphology and $(b)$ components of yield at final harvest Values within rows followed by different letters are significantly different at the 0.05 level of confidence

(a)

Component

Control
$0.9 \mathrm{a}$
$18 \cdot 1 \mathrm{a}$
$7 \cdot 9 \mathrm{a}$
$150 \mathrm{a}$
$33 \cdot 2 \mathrm{a}$

Internode length $(\mathrm{cm})$

Cotyledonary leaf number

Branch number

Specific leaf arca $\left(\mathrm{cm}^{2} \mathrm{~g}^{-1}\right)$

Pod number

$33 \cdot 2 a$

(b)

Component

Control

Trcatment

$\begin{array}{cc}T 1 & T 2 \\ 1.3 \mathrm{~b} & 1.0 \mathrm{a} \\ 16.6 \mathrm{a} & 18.1 \mathrm{a} \\ 6.2 \mathrm{~b} & 8.2 \mathrm{a} \\ 174 \mathrm{~b} & 161 \mathrm{a} \\ 22.9 \mathrm{~b} & 29.4 \mathrm{a}\end{array}$

\begin{tabular}{lrrr} 
& & $(\mathrm{g}$ plant & \\
\hline Stem & $10 \cdot 19 \mathrm{a}$ & $7.82 \mathrm{a}$ & $9.63 \mathrm{a}$ \\
Leaf & $9.40 \mathrm{a}$ & $6.94 \mathrm{a}$ & $8.65 \mathrm{a}$ \\
Pods & $14.80 \mathrm{a}$ & $10 \cdot 51 \mathrm{a}$ & $12 \cdot 10 \mathrm{a}$ \\
Mean pod weight & $0.45 \mathrm{a}$ & $0.46 \mathrm{a}$ & $0.42 \mathrm{a}$ \\
\hline
\end{tabular}

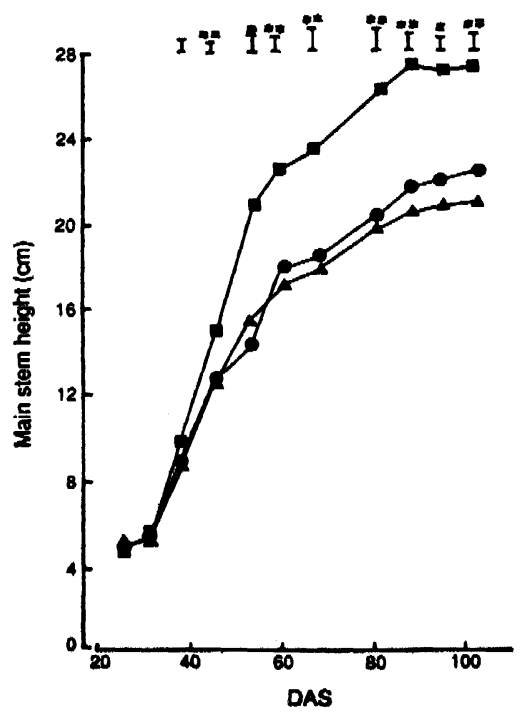

Fig. 2. Seasonal time-courses of main stem

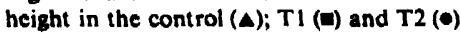
treatments. Vertical bars indicate the standard error of the mean, together with the levels of significance; $P<0.05$ (*) and $P<0.001$ (**) in this and subsequent figures. 
Shading did not affect the rate, but shortened the duration of leaf area expansion in the $\mathrm{T} 1 \mathrm{crop}$, with leaf senescence occurring after 80 DAS (Fig. 3a). A similar but less marked decline in leaf area was observed after 87 DAS in the T2 treatment. Leaf area is strongly influenced by both leaf number and size. Shading did not affect the rate of leaf appearance on the main stem, as is shown by the closeness of the linear regression fitted to the data from all treatments in Fig. $3 b$. Since most leaves in groundnut are borne on lateral branches, the existence of fewer branches at final harvest in the $\mathrm{T} 1$ crop (Table $1 a$ ) suggests a concomitant decline in total leaf number. Leaf size must therefore have been greater in this crop, since no marked reduction in total leaf area was assciated with the smaller number of branches before 80 DAS. This is supported by the significantly greater specific leaf area (SLA) at final harvest found in the $\mathrm{Tl}$ treatment (Table $1 a$ ), confirming previous observations in groundnut and other legumes (Ludlow et al. 1974; Crookston et al. 1975; Ketring 1979; Pallas 1980).
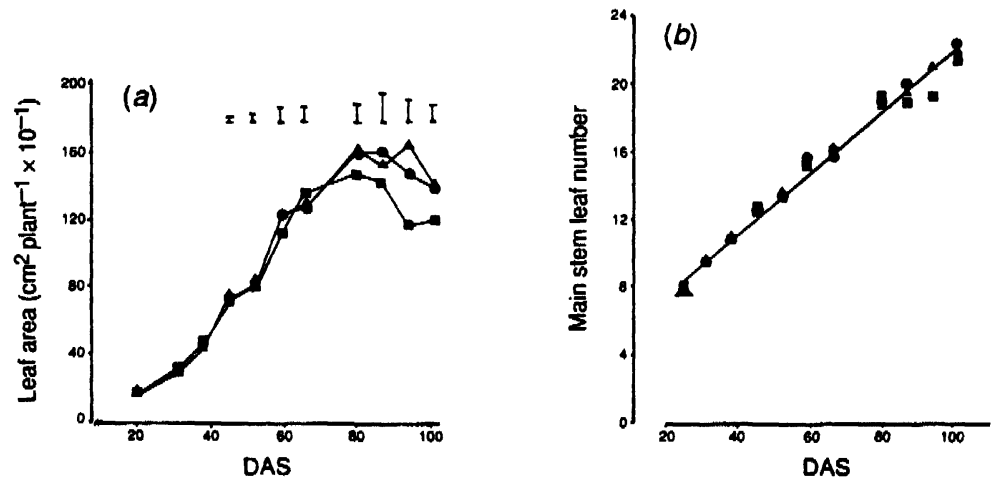

Fig. 3. The effect of shading on (a) leaf area expansion and (b) main stem leaf number. The regression equation ( \pm s.e.m. ) in $(b)$ is $y=4.11( \pm 0.66)+0.18( \pm 0.004) x, r^{2}=0.98$. Symbols as in Fig. 2.

Shading did not delay pod initiation, but the duration of rapid pod development was shorter in the Tl crop, with virtually no new pods being produced after leaf senescence began at 80 DAS (Fig. $4 a$ ). Consequently, pod number at final harvest was significantly lower in the $\mathrm{Tl}$ stand than in the control, but was only marginally reduced in the T 2 crop (Table $1 a$ ). The absence of any significant effect in the latter was presumably because shade was imposed after the onset of rapid pod development when the reproductive sink is being set. Because groundnut is indeterminate, some pods are still immature at final harvest, thereby lowering the "quality' of the economic yield. Although total pod number was significantly lower in the T1 crop (Table $1 a$ ), yield quality was unaffected by shading, since the number of mature pods at final harvest was similar to the control (Fig. $4 b$ ). The reduction in total pod number may have served to ensure that sufficient pods reached maturity, and hence reproductive viability, when assimilate supply was reduced by shading. This view is supported by the greater proportion of mature pods in the T1 $(30.6 \%)$ than in the control $(19.2 \%)$ and $\mathrm{T} 2(16.5 \%)$ crops. 

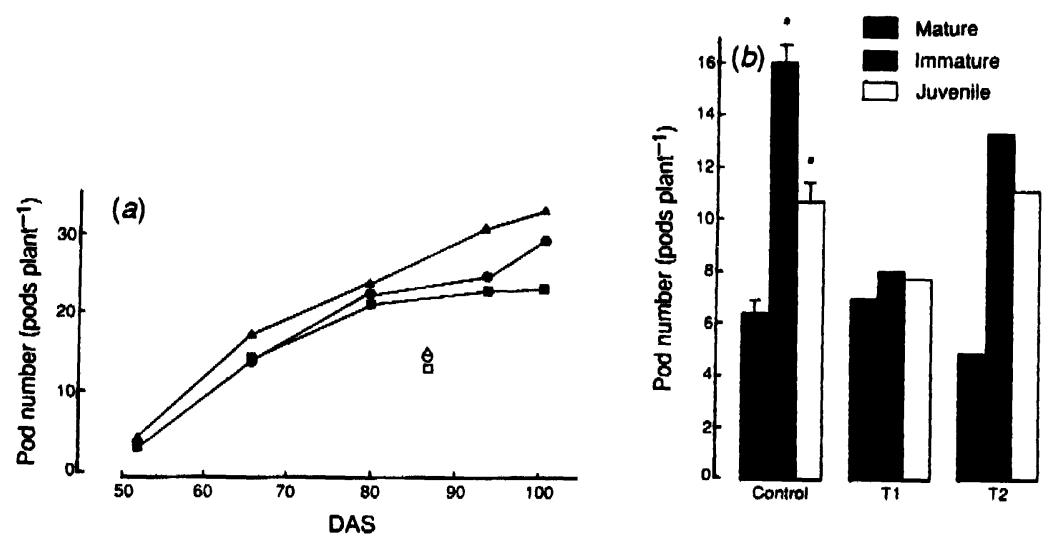

Fig. 4. The effect of shading on (a) cumulative pod number in the control (A), T1 (a) and T2 ( $\bullet$ ) treatments, and $(b)$ the number of mature, immature and juvenile pods per plant at final harvest. In (a) open symbols represent values omitting juvenile pods.

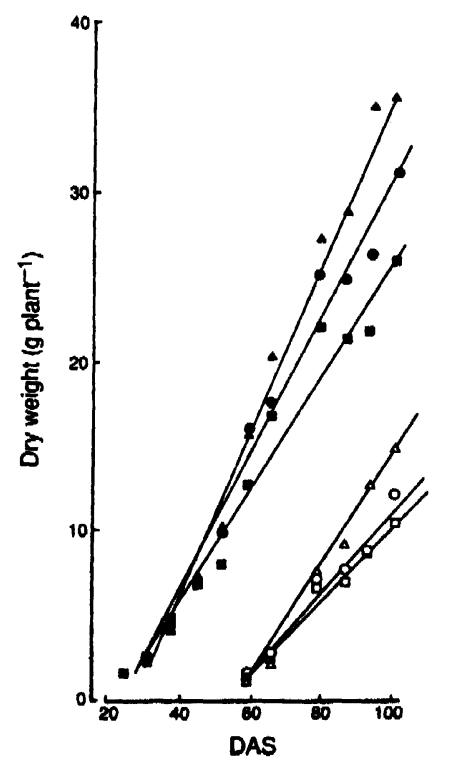

Fig. 5. Cumulative dry matter (closed symbols) and pod weight (open symbols) in the control $(\Delta, \Delta)$, T1 $(a, D)$ and $T 2(\bullet, 0)$ treatments. Linear regressions ( \pm s.c.m.) are:

(l) $y=-13.51 \quad( \pm 1.98)+0.50( \pm 0.02) x ; r^{2}=0.99$

(2) $y=-7.65 \quad( \pm 1.85)+0.34( \pm 0.02) x ; r^{2}=0.98$

(3) $y=-10.06 \quad( \pm 1.97)+0.41( \pm 0.02) x ; r^{2}=0.98$

(4) $y=-17.36 \quad( \pm 1.43)+0.32( \pm 0.02) x ; r^{2}=0.99$

(5) $y=-13.05 \quad( \pm 1.37)+0.22( \pm 0.02) x ; r^{2}=0.98$

(6) $y=-13.39( \pm 1.68)+0.25( \pm 0.02) x ; r^{2}=0.98$.

Since all crops were harvested at 101 DAS, the 20-30\% lower stem, leaf and pod dry weights at final harvest in the $T 1$ and $T 2$ stands (Table $1 b$ ) suggest that shade reduced the rate and/or duration of growth. For most of the season, total dry matter (excluding roots) 
increased at an almost constant rate of $0.50 \mathrm{~g} \mathrm{plant}^{-2}$ day $^{-1}$ in the control crop (Fig. 5), and there was no decline in dry matter production during late pod-fill, presumably because the extended duration of leaf area expansion (Fig. 3a) allowed continued assimilate production. Pod weight also increased at a relatively constant rate $\left(0.32 \mathrm{~g} \mathrm{plant}^{-1}\right.$ day $\left.^{-1}\right)$ in the control plants after $52 \mathrm{DAS}$, although shading interrupted pod growth after $80 \mathrm{DAS}$ in a similar manner to that observed for total dry matter. However, pod weight in the shaded stands again increased at a rate almost identical to the control after 87 DAS. The slopes of the regressions for total and pod dry weights differed significantly $(P<0.001$ and 0.01 respectively) between the control and $\mathrm{TI}$ stands, implying that dry matter production rates were significantly lower in the latter and that the 20-30\% reductions in component dry weights at final harvest (Table $1 b$ ) reflected a real effect of shading. The regressions also differed significantly $(P<0.01$ and 0.05$)$ between the control and T2 stands.

Fig. 6 shows the relation between dry matter production and cumulative intercepted radiation in all treatments between 44 and 94 DAS. Although roots were not included in the analysis, evidence suggests that this omission has little effect on estimates of conversion efficiency (e) except under dry conditions (Azam-Ali et al. 1989). The linear relations give a conversion efficiency of $2.36 \mathrm{~g} \mathrm{MJ}^{-1}$ for the $\mathrm{T} 1$ crop, more than double that of the T2 $\left(1.17 \mathrm{~g} \mathrm{MJ}^{-1}\right)$ and control $\left(0.98 \mathrm{~g} \mathrm{MJ}^{-1}\right)$ crops. Thus, the T1 crop intercepted only about one-fourth as much radiation as the control, but converted this to dry matter 2.41 times more efficiently.

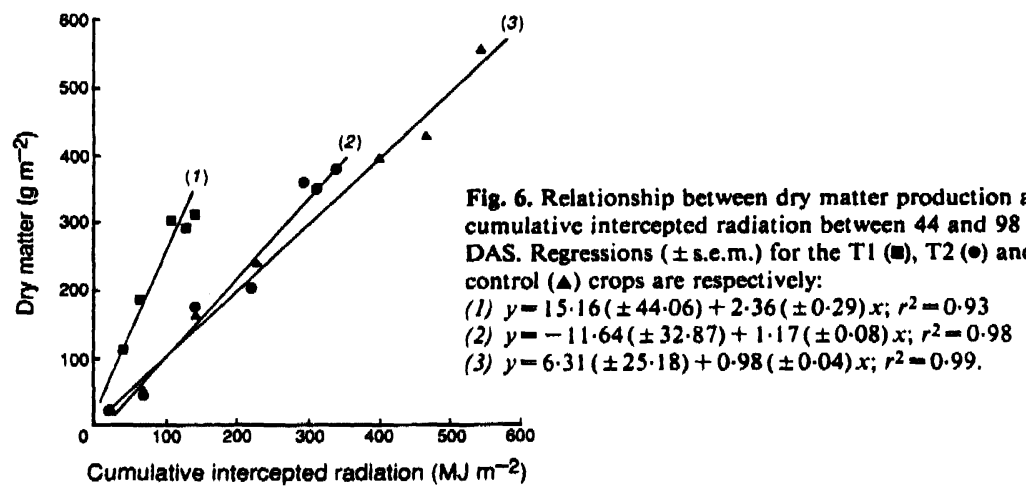

Three linear regressions describe the partitioning of dry matter to the leaves, stems and pods of all crops during reproductive growth (Fig. 7a). The similarity of dry matter partitioning in all treatments is striking, despite the greatly differing durations of shade. The lower yield of the shaded crops was therefore apparently not caused by changes in the partitioning of dry matter to reproductive structures, since the progressive increase in dry matter accumulation by the pods matched the decline in dry matter partitioning to leaves and stems in all treatments. This view is supported by the close correlation between total pod weight and number in all treatments (Fig. $7 b$ ), which suggests that reproductive yield was primarily a function of the number of pods set rather than individual pod weight (Table 16 ). 

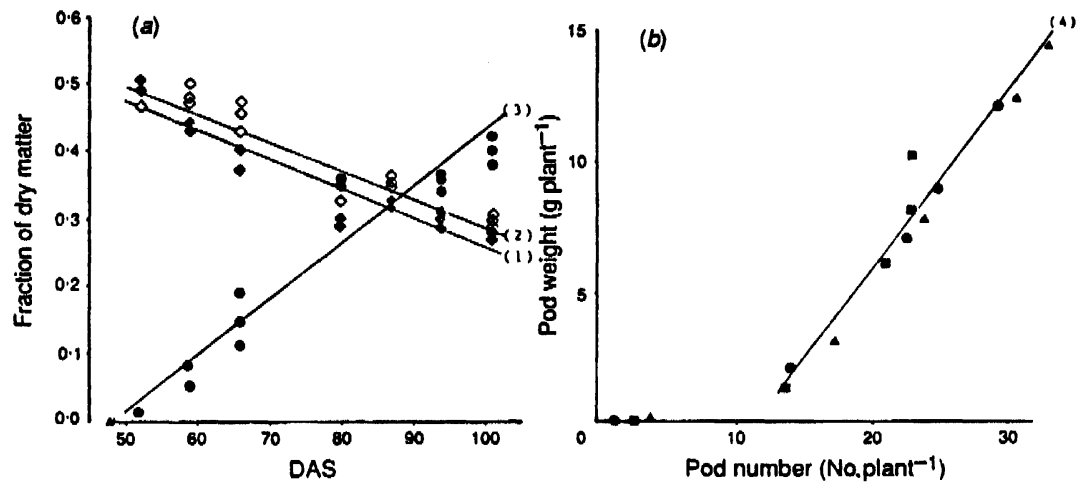

Fig. 7. (a) Dry matter partitioning to leaves $(\diamond)$, stems $(\diamond)$ and pods $(\theta)$ in all stands during the reproductive phase and $(b)$ the relationship between total pod weight and pod number during the linear phase of reproductive growth in the control (A); TI (D) and T2 ( $)$ treatments. The linear regressions ( \pm s.e.m.) fitted to the data for leaves (1), stems $(2)$ and pods $(3)$ in $(a)$ and to all treatments (4) in (b)

(I) $y=0.69 \quad( \pm 0.004)+0.004 \quad( \pm 0.004) \quad x ; r^{2}=0.89$

(2) $y=0.72 \quad( \pm 0.036)+0.004 \quad( \pm 0.000) \quad x ; r^{2}=0.90$

(3) $y=-0.40 \quad( \pm 0.065)+0.008 \quad( \pm 0.000) x ; r^{2}=0.91$

(4) $y=-7.52 \quad( \pm 1.51)+0.67 \quad( \pm 0.05) \quad x ; r^{2}=0.95$.

\section{Discussion}

\section{Vegetative and Reproductive Development}

Plants in the $\mathrm{Tl}$ treatment responded to long-term shade by increasing their height, internode length and specific leaf area (SLA) (Table $1 a$ ). The production of thinner leaves appeared to optimize light interception (Stirling 1988) with minimal assimilate investment in non-photosynthetic tissue, as was indicated by their greater SLA (Table $1 a$ ). The reduced leaf area duration of shaded plants (Fig. 3a) contrasts with previous reports (Ketring 1979) that leaf area was increased in groundnut grown at low as opposed to high irradiance. However, potted plants were used and the maximum irradiance in the control treatment was little more than half that experienced during the rainy season, which may account for the differing response to those observed in field crops (Ludlow et al. 1974; Okoli and Wilson 1986).

The increased plant height (Fig. 2), and hence distance over which pegs must extend to reach the soil, may have been partly responsible for reducing pod number and hence pod yield in the shaded crops (Table 1). There is also evidence that shading reduces the numbers of flowers and pegs produced (Farnham et al. 1986). The lower yield of the T1 crop than in the control reflected its reduced duration of pod development, and hence the number of pods set (Fig. 4a), rather than reductions in mean pod weight (Table $1 b$ ) or mature pod number (Fig. 4b). Hang et al. (1979) reported a similar increase in the percentage of mature pods when groundnut was shaded during reproductive growth, although absolute yield was reduced by the virtual cessation of peg and pod development. Shade imposed only during pod-fill (T2 stand) had less effect on total pod yield despite reducing the percentage of mature pods at final harvest. Since total pod number and hence reproductive sink capacity 
were similar in the T2 and control crops (Table $1 a$ ), the slightly lower number of mature pods in the former (Fig. $4 b$ ) appears to have resulted from source rather than sink-related constraints, in accordance with the views of Farnham et al. (1986).

Shading did not markedly alter the pattern of dry matter partitioning to pods (Fig. $7 a$ ), which constituted approximately $40 \%$ of total dry matter in all crops at final harvest. It therefore appears likely that reduced net assimilation in the shaded crops was a major factor in reducing total dry matter and pod yield.

\section{Dry Matter Production and Light-use Efficiency}

In healthy crops, the rate of growth depends on the quantity of radiation intercepted and the efficiency with which it is converted to dry matter (Biscoe and Gallagher 1977). There have been few studies of the conversion efficiency of shaded groundnut crops, the closest approximation being provided by Simmonds and Ong (1987). In their glasshouse study, mean seasonal radiation receipts were about $9.0 \mathrm{MJ} \mathrm{m}^{-2}$ day-1, similar to the shaded crops in the present study (approximately $8.0 \mathrm{MJ} \mathrm{m}^{-2}$ day-1). Shading throughout reproductive development in the T1 stand produced a conversion efficiency $(2.36 \mathrm{~g} \mathrm{MJ}-1)$ appreciably higher than previously reported for Kadiri-3, the nearest being $1.88 \mathrm{~g} \mathrm{MJ} \mathrm{J}^{-1}$ for an irrigated crop grown in glasshouses at low radiation levels (Ong et al. 1987). Conversion efficiency did not differ significantly between the T2 and control crops (Fig. 6), whose average of $1.07 \mathrm{~g} \mathrm{MJ}^{-1}$ was lower than that of $1.3 \mathrm{~g} \mathrm{MJ}^{-1}$ reported for the same cultivar grown in combination with millet during the rainy season at Hyderabad (ODA 1987).

In this, as in previous studies, $e$ has been calculated from measurements of interception of total as opposed to photosynthetically active radiation (PAR). Although there is no simple conversion between total radiation and PAR within canopies, periodic measurements demonstrated that the spectral quality of the radiation reaching the shaded crops was hardly affected by the bamboo screens (Stirling 1988). Since leaf areas were similar in all treatments until after 80 DAS (Fig. 3a), the conversion efficiencies calculated from measurements of PAR interception would be approximately double those cited here. The absolute values of $e$ should nevertheless be treated with some caution for two reasons. Firstly, the canopy was assumed not to extend beyond the $90 \mathrm{~cm}$ transect in which incoming and transmitted radiation were measured. However, during the period after 87 DAS, corresponding to the last two data points in Fig. 5, the longest cotyledonary branches in the outer rows of the control and T2 crops extended $2-3 \mathrm{~cm}$ beyond the confines of the radiation measurements. During the same period, a small proportion of leaves in the most shaded G3 row of the TI crop grew outside the bamboo screen and therefore experienced irradiances approximately $50 \%$ higher than the rest of the stand. These factors would have caused $e$ to be underestimated for the T2 and control stands and overestimated for the TI crop. Secondly, the calculations of dry matter production were based on the population of approximately 20 plants $\mathrm{m}^{-2}$ present in all stands at final harvest. Since almost $10 \%$ fewer plants survived to final harvest than were present at $19 \mathrm{DAS}$, dry matter production per unit land area may have been underestimated, artificially inflating the estimates of $e$ for all treatments. Nevertheless, it is unlikely that the errors involved were sufficiently large to explain the more than twofold greater conversion efficiency of $\mathrm{Tl}$ than the other stands (Fig. 6).

The greater $e$ values of the shaded plants may be explained by the shape of the photosynthetic light-response curve, which saturates at approximately $1200 \mu \mathrm{mol} \mathrm{m}-2 \mathrm{~s}^{-1}$ in groundnut (ODA 1987). Average irradiances during the central hours of the day during the rainy season in the SAT are typically around $700 \mathrm{~W} \mathrm{~m}^{-2}$, equivalent to about $1600 \mu \mathrm{mol}^{-2}$ $s^{-1}$ of PAR. On the assumption that the bamboo reduced PAR at midday to an extent equivalent to the $46 \%$ reduction in total irradiance, the quantum flux densities incident upon the shaded and unshaded stands would have been approximately 860 and $1600 \mu \mathrm{mol}$ $m^{-2} s^{-1}$. These values suggest that the leaves at the top of the shaded canopies were 
functioning below the photosynthetic light saturation point and hence were operating more efficiently than equivalent light-saturated leaves in the unshaded control crop.

Since leaf area in the TI crop never exceeded that in the control (Fig. 3a), but internode length was significantly greater (Table $1 a$ ), there must have been greater spatial separation of the leaves in the former. Thus a larger proportion of leaves in the more open TI canopy would have been operating nearer to their optimum irradiance owing to the more even distribution of light than in the shorter, more compact control crop. Blad and Baker (1972) reported similar changes in the spatial distribution of leaf area after finding that soybean produced most of its leaf area near the top of the canopy when grown at high irradiance but leaf distribution was more even at low irradiance. Since PAR is rapidly attenuated by species with prostrate leaves, as in groundnut (Monsi and Saeki 1953), maximum interception occurs near the canopy surface. Thus, incident radiation would have been primarily intercepted as direct radiation by the uppermost leaves of the unshaded control stand, whereas a larger proportion of the leaves in the Tl crop would have received increased contributions of diffuse radiation due to the scattering of light by the bamboo screen and its more open canopy structure. Consequently, the higher maximum photosynthetic rate of the unshaded control stand would have been partly offset by the lower mean photosynthetic efficiency resulting from the light saturation of its uppermost leaves. In the T2 stand, shading produced marginal increases in canopy height (Fig. 2) and conversion efficiency (Fig. 6) compared with the control, but the latter was less marked than in the Tl crop, presumably because the canopy remained relatively closed and impervious to light.

Despite its substantially greater conversion efficiency, total dry matter at final harvest was $27 \%$ lower in the TI stand than in the control (Table $1 b$ ). Total dry matter is governed both by the rate and duration of crop growth. Shading apparently reduced both the rate of the linear growth phase (Fig. 5), because the increase in $e$ was insufficient to compensate for the reduced cumulative light interception (Fig. 6), and also the duration of growth by inducing early leaf senescence. The factors causing premature leaf senescence at low irradiances are not known, but in this instance, the additional demand for assimilates imposed by the pods after 80 DAS may have been involved (Nooden 1980). Premature leaf senescence was apparently the main factor limiting dry matter production in the shaded stands. However, even if canopy duration could have been extended in the T1 crop, it is unlikely that pod yield would have been improved greatly since the number of pods set was apparently related to high photosynthetic rates and assimilate available rather than conversion efficiency, and consequently pod yield would have been 'sink-limited'. In contrast, increased canopy duration might well have improved pod yield in the T2 stand, since rapid pod development began prior to the imposition of shading (Fig. 4a), when photosynthetic rates would have been high, thereby providing a larger sink capacity for assimilates than in the $\mathrm{T} 2$ crop late in the season. Thus, although the increased conversion efficiency of shaded plants partially compensated for the reduction in incident radiation, the major limitations to pod yield were the restricted number of pods set in the TI crop and limited assimilate availability during pod-filling in the T2 crop.

\section{Conclusions}

This study suggests that yield losses in intercropped groundnut may be largely explained by the reduced photosynthetic activity of shaded crops. Nevertheless, the greater conversion efficiency of shaded groundnut may well account for the improved light-use efficiency seen in intercrop as opposed to sole cropping systems (Marshall and Willey 1983; Trenbath 1974; Willey and Roberts 1976). The greater proportion of mature pods at final harvest in $\mathrm{Tl}$ than in the other crops suggests that shading throughout the reproductive phase caused earlier maturation. This may prove beneficial when groundnut is intercropped during the short growing seasons of the SAT, by reducing the risk of yield losses 
due to late season drought (Nigan et al. 1980). However, where irrigation is available, the lower yield losses associated with late rather than early shading suggest that intercrop advantages may be increased by growing crops of widely differing durations to minimize shading during the critical stages of early pod development.

\section{Acknowledgments}

We thank Nottingham University and ICRISAT for financing the visit of C.M.S. and staff in Groundnut Physiology at ICRISAT for technical assistance with growth analysis.

\section{References}

Azam-Ali, S. L., Simmonds, L. P., Nageswara Rao, R. C., and Williams, J. H. (1989). Population, growth and water use of groundnut maintained on stored water. III. Dry matter, water use and light interception. Exp. Agric. 25, 77-86.

Biscoe, P. V., and Gallagher, J. N. (1977). Weather, dry matter production and yicld. In 'Environmental Effects on Crop Physiology'. (Eds J. J. Landsberg and C. V. Cutting.) pp. 75-100. (Academic Press: London.)

Blad, B. L., and Baker, D. G. (1972). Reflected radiation from a soybean crop. Agron. J. 64, 27780.

Crookston, R. K., Treharne, K. J., Ludford, P., and Ozbun, J. L. (1975). Response of beans to shading. Crop Sci. 15, 412-16.

Farnham, M. W., Gross, H. D., and Cappy, J. J. (1986). Effect of light level on dinitrogen fixation and carbohydrate distribution in virginia peanuts. Crop Sci. 26, 311-16.

Hang, A. N., McCloud, D. E., Boote, K. J., and Duncan, W. G. (1979). Shade effects on growth, partitioning and yicld components of peanut. Crop Sci. 24, 109-15.

Harris, D., and Natarajan, M. (1987). Physiological basis for yield advantage in a sorghum/groundnut intercrop exposed to drought. II. Plant temperature, water stress and components of yield. Field Crops Res. 17, 273-88.

Harris, D., Natarajan, M., and Willey, R. W. (1987). Physiological basis for yield advantage in a sorghum/groundnut intercrop exposed to drought. 1. Dry-matter production, yicld and light interception. Field Crops Res. 17, 259-72.

Ketring, D. L. (1979). Light effects on development of an indeterminate plant. Plant Physiol. 64, 665-7.

Kou, G. C., Tsay, J. J. S., and Tsuo, S. C. S. (1977). Physiological studies on tropical soybean. Bull. Inst. Trop. Agric., Kyushu University 2, 12-24.

Ludlow, M. M. (1976). Ecophysiology of C4 grasses. In 'Water and Plant Life'. (Eds O. L. Lange, L. Kappen and E. D. Schulze.) pp. 364-86. (Springer-Verlag: Berlin.)

Ludlow, M. M., Wilson, G. L., and Heslehurst, M. R. (1974). Studies on the productivity of tropical pasture plants. V. Effect of shading on growth, photosynthesis and respiration in two grasses and two legumes. Aust. J. Agric. Res. 25, 425-33.

Marshall, B., and Willey, R. W. (1983). Radiation interception and growth in an intercrop of pearl millet/groundnut. Field Crops Res. 7, 141-60.

Matthews, R. B., Saffell, R. A., and Campbell, G. S. (1986). An instrument to measure light distribution in row crops. Agric. Forest Meteorol. 39, 177-84.

Monsi, M., and Sacki, T. (1953). Uber den Lichtfaktor in den PIllazengesellschaften und sein Bedeutung fur die Stofproduction. Japanese J. Bot. 14, 22-52.

Montcith, J. L. (1969). Light interception and radiative cxchange in crop stands. In Physiological Aspects of Crop Yield'. (Ed. J. D. Eastin.) pp. 89-115. (Am. Soc. Agron.: Madison, Wisc.)

Muchow, R. C. (1985). An analysis of the effects of water deficits on grain legumes grown in a semi-arid tropical environment in terms of radiation interception and its efficiency of use. Field Crops Res. 11, 309-23.

Natarajan, M., and Willey, R. W. (1980). Sorghum/pigeonpea intercropping and the effects of plant population density. I. Growth and yield. J. Agric. Sci. 95, S1-8.

Nigam, S. N., Dwivedi, S. L., and Gibbons, R. W. (1980). Groundnut breeding at ICRISAT. Proc. Int. Workshop on Groundnuts, ICRISAT Center, Patancheru, India, 13-17 Oetober 1980, pp. 62-8. 
Nooden, L. D. (1980). Senescence in the whole plant. In 'Senescence in Plants'. (Ed. K. V. Thimann.) pp. 219-58. (CRC Press: Boca Raton, Florida.)

ODA Tropical Microclimatology Unit (1987). 'Introduction, Methods and Principles. Vol. I.' (University of Nottingham, ODA, Eland House; Stag Place, London SWIE SDH.)

Ofori, F., and Stern, W. R. (1987). Cereal-legume intercropping systems. Adv. Agron. 41, 41-90.

Okoli, P. S. O., and Wilson, G. F. (1986). Response of cassava (Manihol esculenta Crantz) to shade under field conditions. Ficld Crops Res. 14, 349-59.

Ong, C. K., Simmonds, L. P., and Matthews, R. B. (1987). Response to saturation deficit in a stand of groundnut (Arachis hypogaea L.). 2. Growth and development. Ann. Bot. 59, 121-8.

Pallas, J. E., Jr (1980). An apparent anomaly in peanut leaf conductance. Plant Physiol. 65, 84851.

Reddy, M. S., and Willey, R. W. (1981). Growth and resource use studies in an intercrop of pearl millet/groundnut. Field Crops Res. 4, 13-24.

Reddy, M. S., Floyd, C. N., and Willey, R. W. (1980). Groundnut in intercropping. Proc. Int. Workshop on Groundnuts, ICRISAT Center, Patancheru, India, 13-17 October 1980, pp. 133-42.

Simmonds, L. P., and Ong, C. K. (1987). Responses to saturation deficit in a stand of groundnut (Arachis hypogaea L.). 1. Water use. Ann. Bot. 59, 113-19.

Stirling, C. M. (1988). Environmental effects on partitioning and development in groundnut. Ph.D. Thesis, Nottingham University.

Thompson, D. R., Monyo, J. H., and Finlay, R. C. (1976). Effects of maize height difference on the growth and yield of intercropped soybeans. In 'Intercropping in Semi-Arid Areas'. (Eds J. H. Monya, A. D. R. Ker and M. Campbell.) (Int. Development Rescarch Centre: Ottawa.)

Trenbath, B. R. (1974). Biomass productivity of mixtures. Adv. Agron. 26, 177-204.

Tsay, J. S., Fukai, S., and Wilson, G. L. (1985). Soybean responses to intercropping with cassava. In 'Soybean in Tropical and Subtropical Cropping Systems'. Proc. Symposium, Tsukuba: Japan, 26 Sept.-1 Oct. 1983, pp. 13-24.

Willey, R. W., and Osiru, D. S. O. (1972). Studies on mixtures of maize and beans (Phaseolus vulgaris) with particular reference to plant population. J. Agric. Sci. 79, 517-29.

Willey, R. W., and Roberts, E. H. (1976). Mixed cropping. In 'Solar Energy in Agriculture'. Proc. Joint Int. Solar Energy Soc. Conf., University of Reading, U.K., pp. 44-7.

Willey, R. W., Natarajan, M., Reddy, M. S., and Rao, M. S. (1986). Cropping systems with groundnut: resource use and productivity. In 'Agrometeorology of Groundnut'. Proc. Int. Symp., ICRISAT Sahelian Center, Niamey: Niger. 21-29 Aug. 1985, pp. 193-205.

Manuscript received 5 July 1989, accepted 17 January 1990 